2. Rastan AJ, Dege A, Mohr M, Doll N, Falk V, Walther T, et al. Early and late outcomes of 517 consecutive adult patients treated with extracorporeal membrane oxygenation for refractory postcardiotomy cardiogenic shock. J Thorac Cardiovasc Surg. 2010;139:302-11.

3. Beurtheret S, Mordant P, Paoletti X, Marijon E, Celermajer DS, Léger P, et al. Emergency circulatory support in refractory cardiogenic shock patients in remote institutions: a pilot study (the cardiac-RESCUE program). Eur Heart J. 2013;34: 112-20.

4. Formica F, Avalli L, Redaelli G, Paolini G. Interhospital stabilization of adult patients with refractory cardiogenic shock by veno-arterial extracorporeal membrane oxygenation. Int J Cardiol. 2011;147:164-5.

5. Formica F, Mariani S, Singh G, D’Alessandro S, Messina LA, Jones N, et al. Postinfarction left ventricular free wall rupture: a 17-year single-centre experience. Eur J Cardiothorac Surg. 2018;53:150-6.

6. Formica F, Corti F, Avalli L, Paolini G. ECMO support for the treatment of cardiogenic shock due to left ventricular free wall rupture. Interact Cardiovasc Thorac Surg. 2005;4:30-2.

7. Squiers JJ, Lima B, DiMaio JM. Contemporary extracorporeal membrane oxygenation therapy in adults: fundamental principles and systematic review of the evidence. J Thorac Cardiovasc Surg. 2016;152:20-32.

8. Fux T, Holm M, Corbascio M, Lund LH, van der Linden J. Venoarterial extracorporeal membrane oxygenation for postcardiotomy shock: risk factors for mortality. J Thorac Cardiovasc Surg. 2018;156:1894902.

9. Formica F, Avalli L, Colagrande L, Ferro O, Greco G, Maggioni E, et al. Extracorporeal membrane oxygenation to support adult patients with cardiac failure: predictive factors of 30-day mortality. Interact Cardiovasc Thorac Surg. 2010; 10:721-6.

10. Avalli L, Sangalli F, Migliari M, Maggioni E, Gallieri S, Segramora V, et al. Early vascular complications after percutaneous cannulation for extracorporeal membrane oxygenation for cardiac assist. Minerva Anestesiol. 2016; $82: 36-43$.

https://doi.org/10.1016/j.jtcvs.2018.11.120

\section{ARTERIAL LACTATE BEFORE INITIATION OF VENOARTERIAL EXTRACORPOREAL MEMBRANE OXYGENATION FOR POSTCARDIOTOMY \\ SHOCK IMPROVES POSTIMPLANT OUTCOME PREDICTION \\ Reply to the Editor:}

The remark of Formica and colleagues in their letter that the level of arterial lactate after the start of venoarterial extracorporeal membrane oxygenation (VAECMO) may also affect short-term survival in patients with refractory postcardiotomy cardiogenic shock (RPCS) contributes to the discussion of the importance of arterial lactate as an overall predictive outcome marker in RPCS. Formica and colleagues refer to their own group's study ${ }^{1}$ of 42 surgical patients who received VA-ECMO for cardiogenic shock. Despite the relatively small number of patients, Formica and colleagues identified the arterial lactate level at 48 hours after VAECMO start as the most significant independent risk factor associated with mortality during VA-ECMO (odds ratio, 2.16; 95\% confidence interval, 1.13-4.14; $P=.019)$. Furthermore, the chosen lactate cut off level
Authors have nothing to disclose with regard to commercial support.

of $3 \mathrm{mmol} / \mathrm{L}(27.0 \mathrm{mg} / \mathrm{dL})$ or greater at 48 hours after VA-ECMO initiation was identified as predictive for 30-day mortality, with a significant difference between survivors and nonsurvivors $(54.8 \%$ vs $14.3 \%$; $P=.001)$. These interesting findings on arterial lactate behavior during VA-ECMO support, from which definite recommendations were not possible because of the limited sample size, were later supported by larger studies specifically focusing on blood lactate levels after VA-ECMO initiation. ${ }^{2-4}$

In contrast, the aim of our study of 105 patients with RPCS supported with VA-ECMO was specifically to identify factors present before VA-ECMO for postimplantation outcome prediction. ${ }^{5}$ Lactate levels during the days after VA-ECMO start are among several factors that obviously are not available to consider before VAECMO is initiated and thus not of any value for postimplantation outcome prediction before VA-ECMO initiation.

Moreover, Formica and colleagues highlight the importance of further analysis of the relationship between presence of ischemic heart disease (IHD) and changes in arterial lactate levels. Considering our focus on factors before VA-ECMO, we have performed an additional subgroup analysis of the 105 patients included in our study comparing the Kaplan-Meier survival curves with an arterial lactate cutoff level of $10 \mathrm{mmol} /$ $\mathrm{L}(90.1 \mathrm{mg} / \mathrm{dL})$ or greater in patients with or without IHD (the cutoff level of $10 \mathrm{mmol} / \mathrm{L}$ or greater was chosen because it corresponds to a specificity of $91 \%$, implying that a lactate level of $10 \mathrm{mmol} / \mathrm{L}$ identified more than $90 \%$ of the patients who died in our study population). The curves illustrate that when separating the cohort between patients with and without IHD, an arterial lactate of $10 \mathrm{mmol} / \mathrm{L}$ or greater had a significant negative impact on survival compared with an arterial lactate less than $10 \mathrm{mmol} / \mathrm{L}$, both in patients with IHD and in those without IHD, as depicted in Figure 1. Furthermore, the lowest 90-day survival (5\%) was seen in patients with a combination of IHD and arterial lactate of $10 \mathrm{mmol} / \mathrm{L}$ or greater (Figure 1, $A$ ). Conversely, patients with absence of IHD and arterial lactate less than $10 \mathrm{mmol} / \mathrm{L}$ had a much higher 90-day survival, $80 \%$ (Figure 1, B).

In conclusion, our additional analysis demonstrated that presence of IHD in these critically ill patients had a severe negative impact on 90-day survival compared 

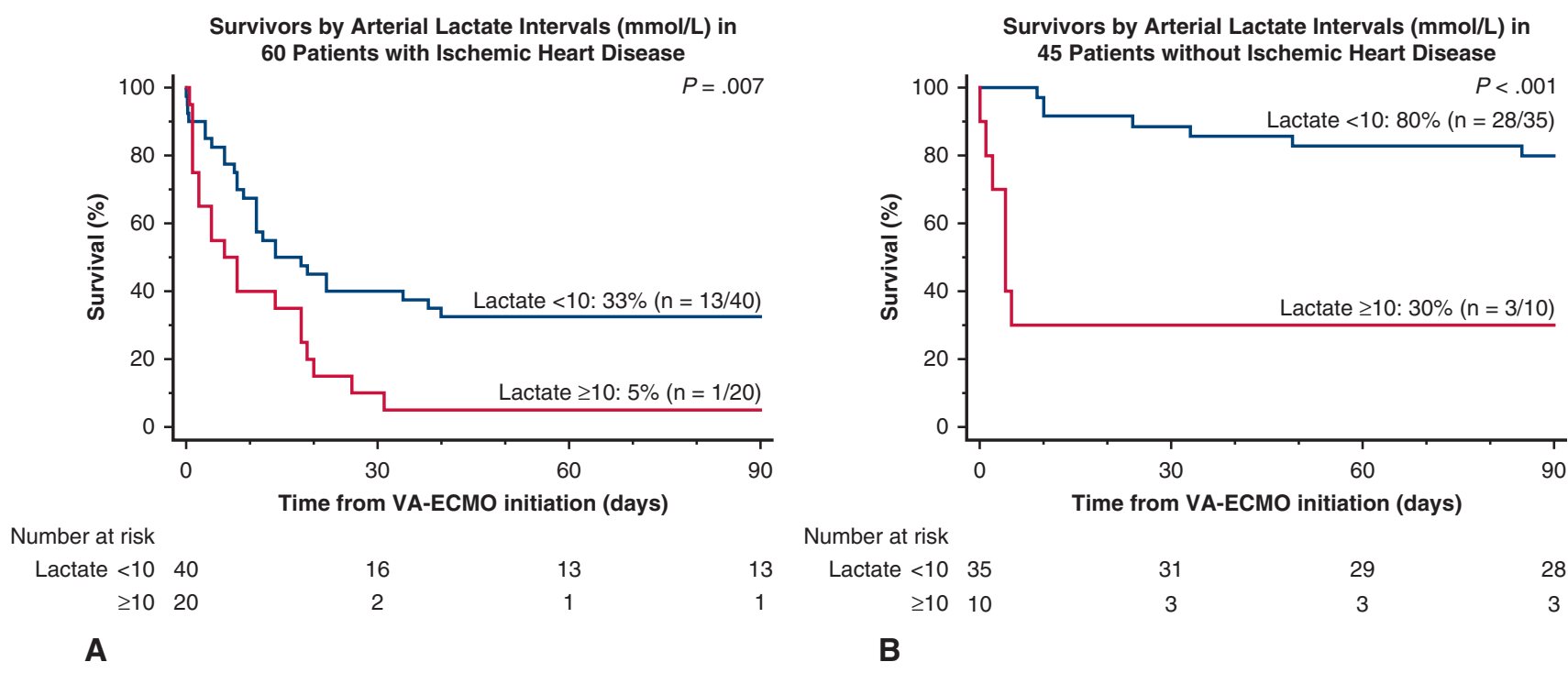

FIGURE 1. Kaplan-Meier survival curves until 90 days after initiation of venoarterial extracorporeal membrane oxygenation $(V A-E C M O)$ support related to arterial lactate intervals and presence of ischemic heart disease (A) and absence of ischemic heart disease (B), at initiation of venoarterial extracorporeal membrane oxygenation in 105 patients with RPCS.

with absence of IHD, especially when IHD was combined with arterial lactate levels of $10 \mathrm{mmol} / \mathrm{L}$ or greater before VA-ECMO.

\section{Thomas Fux, MD, PhD ${ }^{a, b}$ \\ Manne Holm, $M D$, PhD $D^{a, b}$ \\ Jan van der Linden, $M D, P h D^{a, b}$}

${ }^{a}$ Section of Cardiothoracic Surgery and Anesthesiology

Division of Perioperative Medicine and Intensive Care

Karolinska University Hospital

Stockholm, Sweden

${ }^{b}$ Department of Molecular Medicine and Surgery

Karolinska Institutet

Stockholm, Sweden

\section{References}

1. Formica F, Avalli L, Colagrande L, Ferro O, Greco G, Maggioni E, et al. Extracorporeal membrane oxygenation to support adult patients with cardiac failure: predictive factors of 30-day mortality. Interact Cardiovasc Thorac Surg. 2010;10: 721-6.

2. Rastan AJ, Dege A, Mohr M, Doll N, Falk V, Walther T, et al. Early and late outcomes of 517 consecutive adult patients treated with extracorporeal membrane oxygenation for refractory postcardiotomy cardiogenic shock. J Thorac Cardiovasc Surg. 2010;139:302-11.e1.

3. Park SJ, Kim SP, Kim JB, Jung SH, Choo SJ, Chung CH, et al. Blood lactate level during extracorporeal life support as a surrogate marker for survival. J Thorac Cardiovasc Surg. 2014;148:714-20.

4. Li CL, Wang H, Jia M, Ma N, Meng X, Hou XT. The early dynamic behavior of lactate is linked to mortality in postcardiotomy patients with extracorporeal membrane oxygenation support: a retrospective observational study. J Thorac Cardiovasc Surg. 2015;149:1445-50.

5. Fux T, Holm M, Corbascio M, Lund LH, van der Linden J. Venoarterial extracorporeal membrane oxygenation for postcardiotomy shock: risk factors for mortality. J Thorac Cardiovasc Surg. 2018;156:1894-902.e3.

https://doi.org/10.1016/j.jtcvs.2018.12.046

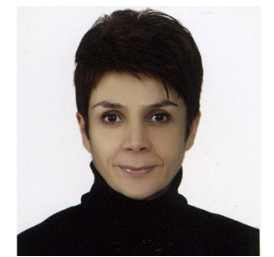

LACTATE MONITORING FOR RISK STRATIFICATION IN POSTCARDIOTOMY PATIENTS WITH EXTRACORPOREAL MEMBRANE

\section{OXYGENATOR SUPPORT}

\section{Reply to the Editor:}

Lactate is a useful marker of clinically relevant tissue malperfusion and cellular hypoxia before the development of catastrophic change in cardiovascular status. The importance of postoperative lactate level measurements, not only for monitoring patients after cardiac surgery but to predict when critically ill patients will require extracorporeal membrane oxygenator (ECMO) support as well. ${ }^{1}$

Hyperlactatemia is known to be associated with adverse outcome with increased mortality and morbidity, and it appears to be related primarily to a state of inadequate perfusion of impaired peripheral microcirculation and endorgan hypoperfusion owing to a low cardiac output. The genesis and pathophysiology of hyperlactatemia are multifactorial in patients with refractory postcardiotomy cardiogenic shock. Hyperlactatemia is a result of both higher production and lower clearance due to the pathologic process during complicated cardiac surgery. Delayed clearance of lactate because of nonischemic hepatosplanchnic hypoperfusion may contribute to high lactate levels. The liver takes up approximately $60 \%$ of the circulating lactate, and most of that lactate is converted back to pyruvate by the hepatocytes. The kidneys are responsible for $30 \%$ of lactate metabolism through gluconeogenesis or complete oxidation; in contrast to the liver, however, the 